\title{
Prof. NN Wig... The Living Legend of Indian Psychiatry
}

\section{${ }^{1}$ Ajit Avasthi, ${ }^{2}$ Subho Chakrabarti}

Professor NN Wig is, in the true sense of the word, a living legend of Indian psychiatry. The Department of Psychiatry at the Postgraduate Institute of Medical Education and Research (PGIMER), Chandigarh, owes its existence to him and his vision continues to guide the staff and students. He single-handedly brought the department into being in 1963 and he continues to be intimately associated with the department and the PGIMER as one of its emeritus professors.

Professor Wig completed his MBBS from KG Medical College, Lucknow, in 1953 and MD Medicine from Lucknow University in 1957. ${ }^{1,2}$ He pursued his interest in psychiatry by training for 4 months at the All India Institute of Mental Health (now The National Institute of Mental Health and Neuro-Sciences, NIMHANS), Bengaluru. On his return, he joined the Medical College at Lucknow as a lecturer in neuropsychiatry. It is here that he started the first general hospital psychiatry unit in India. For 2 years (1961-62), he was on a Rockefeller Foundation Fellowship and received training at the Maudsley Hospital, Institute of Psychiatry, London and the Western Psychiatric Institute, Pittsburgh, United States. He completed Diploma in Psychological Medicine from both England and Scotland during this period.

Dr Wig joined the PGIMER in 1963 and headed the department till 1980. Following this, he was the head of the Department of Psychiatry at the All India Institute of Medical Sciences, New Delhi. ${ }^{3}$ From 1984 till 1990, he was the regional advisor for mental health at the Regional Office for the Eastern Mediterranean (EMRO) of the World Health Organization (WHO) at Alexandria, Egypt. In this capacity, he contributed to the development of mental health programs of 22 countries in the region.

Under his able leadership, the Department of Psychiatry, PGIMER, established itself as one of the leading training and research centers in the country. Its reputation was enhanced in 1976 when the WHO designated

\footnotetext{
${ }^{1}$ Professor and Head, ${ }^{2}$ Professor

1,2Department of Psychiatry, Postgraduate Institute of Medical Education and Research, Chandigarh, India
}

Corresponding Author: Ajit Avasthi, Professor and Head Department of Psychiatry, Postgraduate Institute of Medical Education and Research, Chandigarh, India, Phone: +917087009803, e-mail: drajitavasthi@yahoo.co.in it as a "WHO Collaborating Centre for Mental Health," the first such center in Asia to be accorded this honor. A number of multicentric WHO research projects followed, the most notable among them being the "Strategies for Extending Mental Health Services to Developing Countries" and the "Determinants of Outcome of Severe Mental Disorder (DOSMed)." The

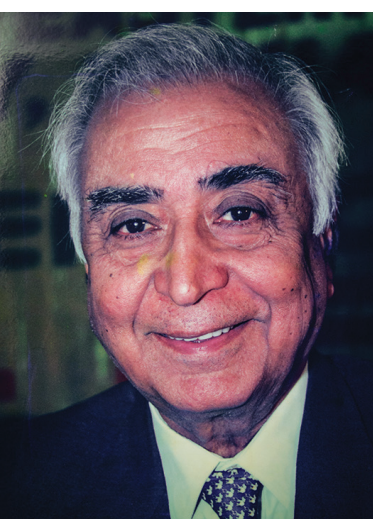

Professor NN Wig community mental health program started in Raipur Rani as a part of these projects eventually provided the model for the National Mental Health Programme in India and inspired similar programs in other developing countries.

Prof Wig's research has been pioneering in a number of ways. Firstly, he was the first psychiatrist to focus on the understanding of mental disorders in India. Secondly, he has led a number of multidisciplinary studies in consultation-liaison with the Departments of Obstetrics and Gynecology, Nephrology, Pediatrics, Neurology, etc. Thirdly, he contributed to the classification of psychiatric disorders in India and at the international level. The continuing leadership of the department in the above areas is a reflection of his futuristic approach to his research work.

Beyond the ambit of the department, Dr Wig contributed immensely to the development of psychiatry in India. ${ }^{4}$ He was the honorary general secretary of the Indian Psychiatric Society from 1968 to 1973. He has made seminal contributions to research in the area of nosology, culture-bound syndromes, course and outcome of psychoses, psychotherapy, and psychology.

His contributions to international psychiatry have been remarkable. Apart from his role as a regional advisor for mental health of the EMRO-WHO, he has been a member of the WHO advisory panel on mental health and a member of the Steering Committee of the World Psychiatric Association's international program to reduce stigma and discrimination due to mental illness.

Professor Wig has many honors to his name, which are too numerous to count though, but two of them particularly stand out. One is the honorary fellowship of the Royal College of Psychiatrists, a rare honor indeed, and the other was naming of a unit after his name at the Fountain House Psychiatric Centre at Lahore. 
Finally, above and beyond his distinguished career, what is noteworthy is the great reverence, respect, and love that he evokes in all those who know him, including his well-known students. ${ }^{4}$ His students have headed or are heading many departments of psychiatry in different parts of India and abroad, and national and international health organizations and professional societies.

This, more than anything else, is what makes him a true legend.

\section{REFERENCES}

1. Wig NN. How I became a psychiatrist: an autobiographical account of early career. Delhi Psychiatry J 2007 Oct;10(2): 160-163.

2. PGIMER. The journey of department (1963-2017). Chandigarh: Department of Psychiatry-PGIMER;. 2017.

3. Brief biodata: Dr. N. N. Wig. Mens Sana Monogr 2005 Nov;3(2):1-2.

4. Srinivasa Murthy, R. Mental health in India 1950-2000: essays in honour of Professor N.N. Wig. Bengaluru: People's Action for Mental Health; 2000. 